\title{
Sulfur Deprivation and Genotype Affect Gene Expression and Metabolism of Onion Roots
}

\author{
John A. McCallum, ${ }^{1}$ Meeghan Pither-Joyce, and Martin Shaw \\ New Zealand Institute for Crop and Food Research Limited, Private Bag 4704, Christchurch, New \\ Zealand
}

\begin{abstract}
AdDitional INDEX WORDs. Allium cepa, sulfate, pungency, gene expression, roots
Abstract. Genetic and environmental factors affect onion (Allium cepa L.) pungency but the molecular basis for this variation is not understood. To initiate molecular analysis of onion sulfur metabolism we isolated cDNAs from onion associated with sulfur assimilation and compared gene expression and sulfur metabolism of mild and pungent onion cultivars. We isolated cDNAs encoding homologues of 5 'adenosine-phosphosulfate (APS) reductase, $\gamma$-glutamylcysteine synthetase and serine acetyl transferase using a homology-based RT-PCR approach. Homologues of high-affinity sulfate transporters and sulfite reductase were isolated from an onion root differential cDNA library enriched for genes upregulated by 48 hours sulfur deprivation. The influence of genotype and sulfur nutrition on root expression of selected genes was measured in an experiment in which a low pungency onion cultivar ('Houston Grano') and a high pungency cultivar ('Canterbury Longkeeper') were grown hydroponically in low $\left(0.1 \mathrm{meq} \cdot \mathrm{L}^{-1}\right)$ or high $\left(4.0 \mathrm{meq} \cdot \mathrm{L}^{-1}\right) \mathrm{sulfate}$ medium and harvested before bulbing. 'Canterbury Longkeeper' contained higher concentrations of $(+)-S$-methyl-L-cysteine sulfoxide in leaf and root than 'Houston Grano' but cultivars did not differ in leaf trans-(+)-S-(1-propenyl)-L-cysteine sulfoxide concentrations. 'Houston Grano' accumulated significantly higher concentrations of total $\mathrm{N}$, nitrate, and basic amino acids in leaves and roots, suggesting these cultivars differ markedly in maintenance of S/N homeostasis. Steadystate transcript levels of APS reductase and high-affinity sulfate transporter in roots were significantly higher (2- to 3fold) at low sulfate. By contrast, steady state levels of ATP sulfurylase transcript were significantly higher at high sulfate levels and in 'Canterbury Longkeeper'. We conclude that differences in regulation of the sulfur assimilation pathway may underlie genetic differences in pungency.
\end{abstract}

Allium vegetables are valued for their unique flavors and medicinal properties which derive from bioactive products formed by hydrolysis of $S$-alk(en)yl cysteine sulfoxides (ACSOs) by the enzyme alliinase (Randle and Lancaster, 2001). The intensity and nature of bioactivity vary greatly within and between Allium species and there is growing interest in understanding this variation at a genetic level to enable breeding, production and processing to better target health and market requirements.

Five ACSOs have been reported from Allium species: (+)-Smethyl-L-cysteine sulfoxide (MCSO), S-ethyl cysteine sulfoxide (ECSO), (+)-S-propyl-L-cysteine sulfoxide (PCSO), trans-(+)$S$-(1-propenyl)-L-cysteine sulfoxide (1-PECSO) and (+)-S-(2propenyl)-L-cysteine sulfoxide (2-PECSO). PCSO, 1-PECSO and 2-PECSO are characteristic of Allium (Bernhard, 1970), but MCSO also occurs in legumes and crucifers (Maw, 1982). Recently Kubec et al. (2000) reported that ECSO occurs in most Allium species. Alliums are also notable for their relatively high content of total S (Nielson et al., 1991) and cysteine (Urano et al., 2000).

Many studies have demonstrated that onion (Allium cepa) varieties vary widely in ACSO content (Randle et al., 1995) and hydrolysis products, (Freeman and Whenham, 1975; Platenius and Knott, 1941; Schwimmer and Weston, 1961). Pungency, as measured by pyruvate analysis, is moderately heritable (Lin et al., 1995; Simon, 1995; Wall et al., 1996) and selection for reduced pungency has led to releases of milder varieties such as 'Texas Grano 1015Y' (Pike et al., 1988). Recently Galmarini et al. (2001) reported RFLP mapping of loci affecting pungency in the cross 'BYG15-23' $\mathrm{x}$ 'AC43'.

Received for publication 7 Feb. 2002. Accepted for publication 5 Apr. 2002. This research was funded by the New Zealand Foundation for Research, Science and Technology. We thank Ruth Butler for statistical assistance, Lyall Simmons for HPLC analysis, and Jane Lancaster (AgriFood Solutions) for critical reading of this manuscript.

${ }^{1}$ To whom correspondence should be addressed; e-mail mccallumj@crop.cri.nz.
The major factor affecting pungency is S supply; higher fertility levels lead to greater intensity due primarily to increased 1-PECSO (Randle, 1992a; Randle et al., 1995). Changing S supply leads to large shifts in partitioning within the plant between sulfate and organic $S$, with pungent cultivars accumulating less S as free sulfate (Randle et al., 1993, 1999). Alliinase levels are also affected by S fertility (Lancaster et al., 2000a). Nitrogen and selenium nutrition have also been shown to interact with S fertility to affect pungency (Kopsell and Randle, 1999; Randle, 2000).

Labeling studies suggest that, in onion, glutathione is the major precursor of ACSOs and that biosynthesis proceeds via $\gamma$ glutamyl peptides, which are hydrolyzed to free ACSOs by $\gamma$ glutamyl-transpeptidase (Lancaster and Shaw, 1989). To date, only biochemical characterization of oxidase (Ohsumi et al., 1993) and transpeptidase (Lancaster and Shaw, 1994) enzymes involved in this pathway has been reported.

By contrast, the $\mathrm{S}$ assimilation pathway in higher plants leading to glutathione is now well established (Leustek et al., 2000). Sulfate is actively transported into root cells via highaffinity sulfate transporters. Subsequent reduction and assimilation into cysteine occurs in plastids, where sulfate is activated by ATP sulfurylase to 5'adenosine-phosphosulfate (APS) before undergoing two-step reduction to sulfide catalyzed by APS reductase and sulfite reductase. Cysteine synthetase catalyses the formation of cysteine from sulfide and O-acetyl serine, which is produced by serine acetyltransferase. Molecular characterization of this pathway in Allium has so far been restricted to cloning of cysteine synthase and serine acetyltransferase (Urano et al., 2000) and biochemical characterization of sulfite reductase (Takahashi et al., 1996a, 1996b) in A. tuberosum.

Because of the significance of $S$ to Allium crops and the known complexity of phenotypic responses to $S$ nutrition, our goal was to initiate molecular analysis of onion $\mathrm{S}$ assimilation. We specifically tested the hypothesis that differences in pungency might be 
Table 1. Onion cDNAs encoding homologs of sulfur assimilation genes. Full-length clones isolated by cDNA library screening.

\begin{tabular}{|c|c|c|c|c|c|}
\hline $\begin{array}{l}\text { Clone } \\
\text { homology }\end{array}$ & $\begin{array}{l}\text { RT-PCR } \\
\text { primer }\end{array}$ & $\begin{array}{l}\text { Size } \\
\text { (bp) }\end{array}$ & aa & $\begin{array}{c}\text { Genbank } \\
\text { accession }\end{array}$ & $\begin{array}{l}\text { Amino acid homology } \\
\% \text { and species } \\
\text { of closest match }\end{array}$ \\
\hline APS Reductase & 5' AGGATGTTGCTCTTATHGARTAYG & & & & \\
\hline \multirow[t]{2}{*}{$\gamma$-glutamyl cysteine synthetase } & 5' TAAGGCTGTTGCTGARGARATG & & & & \\
\hline & 3' AGTAAGATGATTTTCCCARTCRTT & 1912 & 496 & AF401621 & 87, Lycopersicon esculentum \\
\hline
\end{tabular}

associated with differences in regulation of the $\mathrm{S}$ assimilation pathway. We confined our attention to studies of onion plants before bulbing to simplify RNA isolation and other quantitative studies and focused primarily on roots because, despite their significance in nutrient assimilation, their role in Allium S metabolism has been little studied to date. To provide the tools for molecular analysis we cloned onion homologues of key genes in the $\mathrm{S}$ assimilation pathway by homology and by screening a differential cDNA library from onion roots enriched for genes upregulated by $\mathrm{S}$ deprivation. We then compared root gene expression and $\mathrm{S}$ metabolism in a mild and a pungent onion cultivar before bulbing to identify genotypic differences.

\section{Methods and Materials}

Plant material. We compared two lines of bulb onion (Allium cepa): 'Canterbury Longkeeper' (CLK), which is an open-pollinated selection from 'Pukekohe Longkeeper' (Crop and Food Research, unpublished data), and an inbred line derived by one round of selfing from 'Houston Grano' (Houston). These exhibit high and low pungency phenotypes respectively, when grown under field conditions with ample S supply. In earlier trials replicated over two sites in 1998-99 these cultivars exhibited pungency ranges of 8.3 to 10.1 and 4.4 to $8.1 \mu \mathrm{mol}$ pyruvate $/ \mathrm{mL}$ juice respectively (McCallum et al., 2001a).

Hydroponic CULTURE-GENERAL. Seeds were germinated for $72 \mathrm{~h}$ at $25^{\circ} \mathrm{C}$, transferred to horticultural foam blocks hydrated with tap water, and transplanted into hydroponic culture at the flag leaf stage. Plants were grown in a glasshouse in Christchurch, New Zealand, at latitude $43^{\circ} \mathrm{S}$ without supplementary lighting. Hydroponic conditions and practices were followed as described previously (Lancaster et al., 2001; Randle et al., 1995) except that 18 plants were grown per 20-L tub. Only sulfate and chloride varied between treatments. The hydroponic solution was changed at biweekly intervals.

Experiment 1: Transient S DePrivation. Plants of CLK were transplanted on 14 August 1999 into four tubs containing 4.0 $\mathrm{meq} \cdot \mathrm{L}^{-1} \mathrm{~S}$ and grown until 10 October. Then solutions in two tubs were changed to $0 \mathrm{meq} \cdot \mathrm{L}^{-1} \mathrm{~S}$ and control tubs were changed to fresh $4.0 \mathrm{meq} \cdot \mathrm{L}^{-1} \mathrm{~S}$ medium. After $48 \mathrm{~h}$ root tissue from $\mathrm{S}$ deprived and control treatments were collected simultaneously, rinsed in distilled water and immediately frozen in liquid $\mathrm{N}_{2}$.

Experiment 2: Steady-state S Deprivation. Extreme high and low S fertility levels were chosen based on earlier work (Freeman and Mossadeghi, 1970; Lancaster et al., 2000a; Randle et al., 1995). Seedlings of CLK and Houston were transplanted on 29 Aug. 2000 into hydroponic culture tubs containing high S (4 meq $\cdot \mathrm{L}^{-1} ; \mathrm{N}: \mathrm{S}$ ratio $\left.=7.5\right)$ or low $\mathrm{S}\left(0.1 \mathrm{meq} \cdot \mathrm{L}^{-1} ; \mathrm{N}: \mathrm{S}\right.$ ratio $\left.=300\right)$ solutions. The experimental unit was 18 plants in a tub and tubs were laid out in a randomized complete block design with five replications per cultivar/S combination to give a total of 20 tubs. Plants were harvested on 28 Oct. when plants were at a spring onion stage before commencement of bulbing and immediately frozen in liquid $\mathrm{N}_{2}$. Subsamples were freeze-dried, ground to a powder and analyzed for $\mathrm{C}, \mathrm{N}$, and $\mathrm{S}$ content using a $\mathrm{S}$ analyzer (Leco Corp., St Joseph, Mich.). For ACSO analysis root and leaf samples were directly extracted in 12 methanol : 5 chloroform : 3 water (by volume) and ethanol ( $80 \%$ v/v) (Lancaster and Kelly 1983 ) and free ACSOs and amino acids were analyzed by reversephase HPLC (Randle et al., 1995). Amino acid and sulfoxide composition of selected extracts was confirmed by qualitative TLC with authentic standards according to Lancaster and Kelly (1983). For anion analysis, aliquots of root extracts used for ACSO analysis were diluted, before addition of internal standard and ion exchange, with deionized water at a ratio of 1:100 for sulfate and either 1:200 or 1:400 for nitrate and centrifuged at $14000 \mathrm{~g}_{\mathrm{n}}$ for $15 \mathrm{~min}$. Diluted samples were analyzed by capillary ion electrophoresis as reported previously (Lancaster et al., 2001). Data for each variate in this experiment was analyzed with analysis of variance using GenStat for Windows, Release 4.2, 5th ed. (VSN International Ltd, Oxford).

Homology CLONING OF cDNAs. Total RNA was extracted from root tissue of hydroponically grown CLK root as described previously (Lancaster et al., 2000b; McCallum et al., 2001b). Reverse transcription was performed on $2 \mu \mathrm{g}$ of total RNA with Oligo (dT) $)_{12-18}$ primer and Superscript II RnaseH-Reverse Transcriptase (Gibco-BRL), according to the manufacturer's instructions. Primer pairs (Table 1) were designed from highly conserved regions of amino acid sequence using the COnsensusDEgenerate Hybrid Oligonucleotide Primers (CODEHOP) strategy (Rose et al. 1998) and Tm calculated with Primer Premier Mini (Premier Biosoft International). Touchdown PCR was carried out starting $5^{\circ} \mathrm{C}$ above the Tm of the primer pair and reducing to $5^{\circ} \mathrm{C}$ below the Tm over 20 cycles, followed by 30 cycles at 5 ${ }^{\circ} \mathrm{C}$ below the Tm. Products were gel purified with Qiaex II Gel Extraction System (Qiagen) and cloned into pGEM-T Easy vector (Promega). Probes from partial cDNA clones were used to screen a root cDNA library for full-length transcripts as described previously (Lancaster et al., 2000b).

3' RACE. RNA extraction and reverse transcription were carried out as described above using an Oligo dT adaptor primer (CACGCGTATCGATGTCGAC $\left.(\mathrm{T})_{18} \mathrm{~V}\right)$. First round PCR was performed with a gene specific primer (Table 2) and the general primer PCR Anchor (CACGCGTATCGATGTCGAC) identical to the 5 ' end of the Oligo dT adaptor primer. PCR $(50 \mu \mathrm{L})$ was carried out on $2 \mu \mathrm{L}$ of the RT reaction with FastStart Taq DNA polymerase (Roche) under recommended conditions for 1 cycle of $94{ }^{\circ} \mathrm{C}$ for $5 \mathrm{~min}$ followed by 30 cycles of $94^{\circ} \mathrm{C}$ for $30 \mathrm{~s}, 60^{\circ} \mathrm{C}$ for $1 \mathrm{~min}$ and $72^{\circ} \mathrm{C}$ for $1 \mathrm{~min}$. A second round of PCR $(100 \mu \mathrm{L})$ was performed on $1 \mu \mathrm{L}$ of the initial PCR with a nested gene 
Total RNA Stain

Sybr Green II

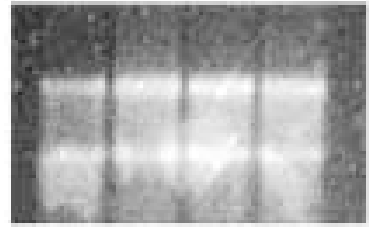

Major transcript size (kbp)

High affinity sulfate transporter

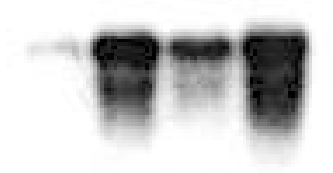

ATP sulfurylase

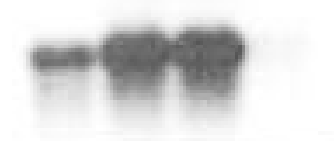

APS

Reductase

Sulfite reductase

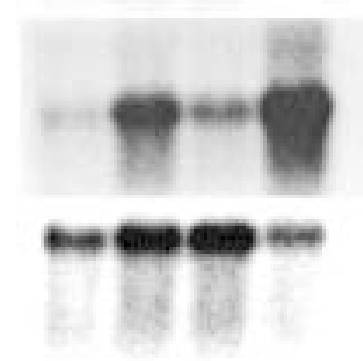

1

\section{$\begin{array}{lll}2 & 3 & 4\end{array}$}

Fig. 1. Northern blot analysis of expression of sulfate assimilation transcripts in roots of onion 'Canterbury Longkeeper' subjected to transient and steady-state sulfur deprivation. Lanes contained pooled total RNA as follows: lane $1=$ Expt. 1 control ; lane 2 = Expt. 1 sulfate deprived; Lane $3=$ Expt. 2 high sulfate; lane $4=$ Expt. 2 low sulfate. Estimated sizes of transcripts in kilobases are indicated on right.

specific primer (Table 2) and the general primer PCR Anchor. PCR was carried out as above except cycle number was increased to 40 . PCR product was purified, cloned and sequenced as above.

SUbTRACTED cDNA LIBRARY CONSTRUCTION. Total RNA was extracted from S-deprived and control treatment CLK roots from Expt. 1 using TRIZOL Total RNA Isolation Reagent (GibcoBRL). The mRNA fraction was isolated using the PolyATtract mRNA Isolation Kit (Promega). cDNA synthesis and subtraction were performed with the PCR-Select cDNA subtraction kit (Clontech), followed by 27 cycles of primary PCR and 12 cycles of secondary PCR using Advantage cDNA polymerase mix (Clontech), according to the manufacturer's instructions. To enrich for genes up-regulated by $\mathrm{S}$ deprivation, a reverse subtracted cDNA library was made using the S-deprived root cDNA pool as the tester and control root cDNA as the driver. Subtraction efficiency was determined by Southern blot analysis of the unsubtracted and subtracted products with the housekeeping gene tubulin (AA451549.1), and with ATP sulfurylase (AF212154) (McCallum et al., 2001b). Subtraction products were ligated into pGEM-T Easy vector (Promega), and 500 clones were randomly chosen for sequencing.

DNA SEQUENCING AND DATA ANALYSIS. Template preparation and sequencing were carried out by the Australian Genome Research Facility (AGRF) Brisbane, Australia. Reactions were performed with M13 reverse primer using ABI PRISM Big Dye terminator chemistry (Applied Biosystems) and analyzed on an ABI377 automated sequencer. Vector and linker sequences were removed using Sequencher (Gene Codes Corporation). Deduced amino acid sequence comparisons were carried out against the nonredundant NIH databases using batch-wise BLASTX searches with Netblast (Altschul et al., 1990) and putative homologues were assigned to sequences with BLASTX match scores over 40. Sequence-based clustering was carried out using UICLUSTER2 (http://eyeball.eng.uiowa.edu/clustering/) with default parameters.

Hybridization analysis. For dot blot analysis, $5 \mu \mathrm{g}$ of total RNA was denatured in $10 \mathrm{~mm} \mathrm{NaOH}, 1 \mathrm{~mm}$ EDTA and applied by vacuum onto Zeta-Probe membrane (Bio-Rad) using a Bio-Dot microfiltration apparatus (Bio-Rad). Probe DNA was hybridized as described previously (Lancaster et al. 2000b), followed by washes at $65^{\circ} \mathrm{C}$ for $30 \mathrm{~min}$ of $2 \times \mathrm{SSC}, 0.1 \% \mathrm{SDS}$ and $1 \times \mathrm{SSC}$, $0.1 \%$ SDS. Membranes were cut up into individual dots and placed in a microtube with $0.5 \mathrm{~mL}$ scintillation fluid and counted on a MicroBeta Scintillation Counter (Wallac). An actin homologue from the differential library was used (BI095607) as a control probe. For Northern blot analysis, $10 \mu \mathrm{g}$ of total RNA was separated on a $1 \%(\mathrm{w} / \mathrm{v})$ denaturing formaldehyde agarose gel and transferred to Zeta-Probe membrane (Bio-Rad) by capillary elution. Hybridization was carried out as for dot blot analysis and autoradiography signals were obtained after exposure to x-ray film at $-80^{\circ} \mathrm{C}$ with intensifying screens.

\section{Results}

Cloning cDNAs associated With SUlfate assimilation AND DEPRIVATION RESPONSE. We amplified and cloned sequences homologous with higher plant APS reductase (APSR), $\gamma$-glutamyl

Table 2. Onion cDNAs encoding homologs of sulfur assimilation genes. Partial clones isolated by differential cDNA cloning and 3' RACE.

\begin{tabular}{|c|c|c|c|c|c|}
\hline $\begin{array}{l}\text { Clone homology } \\
\text { and label }\end{array}$ & $\begin{array}{l}\text { 3' RACE } \\
\text { primers }\end{array}$ & $\begin{array}{l}\text { Size } \\
\text { (bp) }\end{array}$ & aa & $\begin{array}{l}\text { Genbank } \\
\text { accession }\end{array}$ & $\begin{array}{l}\text { Amino acid homology } \\
\% \text { and species } \\
\text { of closest match }\end{array}$ \\
\hline $\begin{array}{l}\text { High-affinity sulfate } \\
\text { transporter (ACS60-JM3.B12) } \\
\text { High-affinity sulfate }\end{array}$ & Differential library cDNA & 249 & 83 & BM192995 & 83, Zea mays \\
\hline transporter (HAST 1) & $\begin{array}{l}\text { Round } 1 \text { CACGGCCGTATCAAACATAG } \\
\text { Round } 2 \text { CGATTTCATGGCTTGTATGG }\end{array}$ & 786 & 189 & AF458090 & 72, Hordeum vulgare \\
\hline sulfite reductase $(1-12)$ & $\begin{array}{l}\text { Round } 2 \text { GGGAAATAAGAATCAGTGGTGA } \\
\text { Round } 1 \text { TGATATTCTCAAAAGGGTGCAA } \\
\text { Round } 2 \text { GGAAATAAGAATCAGTGGTGA }\end{array}$ & 619 & 95 & AF403293 & 74, Nicotiana tabacum \\
\hline
\end{tabular}


Table 3. cDNAs of relevance to sulfur, nitrogen and carbohydrate metabolism identified in sulfate-deprived onion root differential cDNA library.

\begin{tabular}{ll}
\hline \hline Homology & Genbank accession \\
\hline SS1Ft & BI095560 \\
Invertase & BI095773 \\
SiR & BI095555 \\
ATP sulfurylase & BI095588 \\
High-affinity sulfate transporter & BI729471 \\
ABC transporter & BI095695 \\
DNAJ Chaperone & BM192993 BI095528 BI095859 \\
Nitrate transporters & BI095612 BI095822 BM192972 \\
Glutamine synthetase & BI095786
\end{tabular}

cysteine synthetase and serine acetyl transferase (SAT) from onion root cDNA pools using primers designed from conserved regions of these genes. Using these clones as probes we isolated full-length cDNAs from an onion root cDNA library (Tables 1 and 2). Preliminary efforts to clone high-affinity sulfate transporters (HAST) using this technique were unsuccessful.

Because other workers had reported that expression of ATP sulfurylase and HAST is coordinately up-regulated by S deficiency in other species (e.g., Bolchi et al., 1999), we used a differential cDNA cloning strategy to isolate HAST and cDNAs for other genes induced by $\mathrm{S}$ deficiency in onion roots. Before library preparation, S-deprived and control RNA pools were compared by Northern blot analysis with the ATP sulfurylase probe, confirming up-regulation of ATP sulfurylase expression (Fig. 1). Southern analysis of the subtracted pool with the same probe confirmed removal of background, and that amplification of this gene was successful (not shown). Quality and composition of the library were assessed further by sequencing 500 randomly selected clones. We deposited sequences of 475 clones for which sequence of acceptable length and quality were obtained in Genbank EST division under accession numbers BI095502BI095866; BI729433-BI729485; BM114118-BM114147; BM192962-BM193002. Insert sizes ranged from 110 to $720 \mathrm{bp}$. Sequence-based clustering revealed $<20 \%$ redundancy with 382 sequences forming primary clusters. Out of 475 clones 103 matched conserved hypothetical proteins (mostly Arabidopsis) and 110 showed no (or very weak) matches to Genbank databases in December 2001. Inspection of BLASTX matches suggests that transcripts commonly associated with responses to nutrient and other abiotic stresses, such as secondary metabolism, hormone metabolism (ethylene, jasmonate, sterols) and membrane transport, are common in this library.

Clones encoding genes involved in S, N, and carbohydrate metabolism are listed in Table 3. Single clones were identified with similarity to ATP sulfurylase, HAST and ferredoxin-sulfite reductase (SiR). The Sir homologue ACS12-JM3.B09(BI095555) only shares 104 bp homology with higher plant SiRs, which includes a premature stop, suggesting this cDNA is an expressed pseudogene or alternatively spliced transcript. By designing primers from the partial HAST and SiR cDNAs we amplified 3' coding regions of these genes from root and leaf cDNA pools, respectively, by 3' RACE (Tables 1 and 2). In contrast to ACS12JM3.B09, the SiR 3' RACE products (AF403293, AF403294) amplified from onion leaf cDNA contained uninterrupted open reading frames (ORFs) with high homology to plant SiRs.

Clone ACS50-JM5.A10 shows homology with ATP binding cassette $(\mathrm{ABC})$ type transporters, which have been implicated in the transport of sulfates and thiols across vacuolar membranes (Rea et al., 1998) and may be important in maintaining glutathione homeostasis (Foyer et al., 2001). Clones with homology to nitrate transporters and glutamine synthetase were also identified. Chaperones of the DNAJ type have been previously identified in functional screens of Arabidopsis cDNAs conferring resistance to oxidative stress (Kushnir et al., 1995). Their presence in this library may also reflect involvement in maintaining glutathione homeostasis.

EFFECT OF STEADY-STATE S DEPRIVATION ON S AND S METABoLISM OF ONION CULTIVARS. Plants at the low $\mathrm{S}$ treatment level did not show visual signs of S deficiency except for reduced productivity (Table 4), as previously observed (Randle et al., 1995). Elemental analysis showed that total $\mathrm{S}$ content of leaves and roots was much lower in the low $\mathrm{S}$ treatment, but carbon content was not. Free sulfate in roots was reduced to insignificant levels by the low $\mathrm{S}$ treatment, and, at high $\mathrm{S}$, sulfate and total $\mathrm{S}$ were higher in Houston roots. Free nitrate concentrations in Houston roots were $50 \%$ higher than in CLK roots, and total $\mathrm{N}$ of CLK root and leaf was significantly lower than in Houston at low $\mathrm{S}$.

HPLC analysis showed that the cultivars differ markedly in partitioning of $\mathrm{S}$ and $\mathrm{N}$ into ACSOs and basic amino acids. Roots contained low levels of MCSO and traces of PCSO but no detectable 1-PECSO. We tentatively identified ECSO but only on the basis of retention time and therefore data for this sulfoxide should be regarded with caution. The concentrations of root MCSO were lower than those we have reported in older onions (Lancaster et al., 2000b). MCSO concentrations in root and leaf were significantly lower at low $\mathrm{S}$ and concentrations in CLK at high $S$ were twice those in Houston. Leaf 1-PECSO concentrations were also significantly lower at low $\mathrm{S}$, but there was no significant difference between cultivars. Concentration of asparagine and glutamine in roots and leaves was significantly higher at low $\mathrm{S}$ and in Houston.

NORTHERN ANALYSIS OF GENE EXPRESSION UNDER TRANSIENT AND STEADY-STATE $S$ DEPRIVATION. We semiquantitatively compared levels of transcripts for genes encoding steps leading up to cysteine synthesis in roots of CLK subjected to transient and steady-state $S$ deprivation in the two experiments by Northern blotting (Fig. 1). Accumulation of HAST and APSR transcripts was strongly increased by $48 \mathrm{~h}$ of $\mathrm{S}$ deprivation and ATP sulfurylase increased to a lesser extent, compared to controls in which S levels were ample. HAST and APSR transcript levels were also higher in CLK roots under the steady-state deprivation treatment. However in contrast to the transient deprivation treatments, ATP sulfurylase transcript levels were lower under steadystate deprivation. Northern analysis did not show significant differences in SiR expression between the different treatments.

DOT-BLOT ANALYSIS OF GENE EXPRESSION UNDER STEADY-STATE S DEPRIVATION. Quantitative dot-blot analysis of root transcript levels was carried out using probes that revealed strong Northern hybridizations (Table 4). The tubulin probe utilized initially as a control showed a significant $S$ treatment effect, in contrast to the actin probe, confirming that the latter is a suitable control for onion root expression studies. Transcript levels of APSR and HAST were 2- to 3-fold higher at the low S treatment and ATP sulfurylase expression was higher at the high S, confirming the trends observed on Northern blots. HAST transcript levels were significantly higher in Houston roots and ATPs transcript levels were higher in CLK roots. SiR and SAT transcript levels were not affected by $\mathrm{S}$ treatment but SS1FT levels were higher at high $\mathrm{S}$. Transcript levels of SiR and SAT did not significantly vary in 
response to $\mathrm{S}$ treatments but $\mathrm{SiR}$ levels were higher in CLK. Root alliinase transcript levels were significantly higher in Houston at low S.

\section{Discussion}

We previously reported isolation of onion ATP sulfurylase (McCallum et al., 2001b) and now isolation of homologs of all genes in the sulfur assimilation pathway leading to glutathione, with the exception of cysteine and glutathione synthetases. Homologs of these have since been identified in an onion bulb cDNA library (C. Kik and H. Sandbrink, personal communication) The cDNA sequences isolated in this study doubled the number of onion gene sequences in public databases (January 2002) and will provide a valuable source of molecular tools for genetic and metabolic analysis in Allium. Our analysis of the root differential cDNA library suggests that it is of good quality and contains transcripts of relevance to nutrient deficiency and generalized stress responses. Further differential screening would be worthwhile to identify transcripts specifically up-regulated by $\mathrm{S}$ deficiency. Because it is slow and difficult to develop gene mapping populations in Allium, the use of candidate gene approaches in mapping or genetic analysis of traits such as pungency is particularly desirable. We have shown that onion cDNAs may be readily converted to markers for genetic analysis using nonradioactive PCR-SSCP (McCallum et al., 2001b) and are developing markers

Table 4. Treatment means and ANOVAF probabilities for comparison of composition and root gene expression in plants of 'Canterbury Longkeeper' and 'Houston Grano' onions grown under low or high sulfate conditions in Expt. 2.

\begin{tabular}{|c|c|c|c|c|c|c|c|c|}
\hline \multirow{2}{*}{$\begin{array}{c}\text { Line } \\
\text { TREATMENT }\end{array}$} & \multicolumn{2}{|c|}{ CLK } & \multicolumn{2}{|c|}{ Houston } & \multirow[b]{2}{*}{$\begin{array}{l}\text { LSD }(5 \% \\
\text { level, } 12 \\
\text { df) }\end{array}$} & \multicolumn{3}{|c|}{ ANOVA F-probabilities } \\
\hline & High $\mathrm{S}$ & Low $\mathrm{S}$ & High $\mathrm{S}$ & Low $\mathrm{S}$ & & $\begin{array}{c}\text { Sulfate } \\
\text { main effect }\end{array}$ & $\begin{array}{l}\text { Line main } \\
\text { effect }\end{array}$ & $\begin{array}{c}\text { Line } \mathrm{x} \\
\text { sulfate } \\
\text { interaction } \\
\end{array}$ \\
\hline \multicolumn{9}{|l|}{ g fwt per tub } \\
\hline Leaves & 711 & 365 & 768 & 398 & 153 & $<0.001$ & 0.379 & 0.816 \\
\hline Roots & 170 & 142 & 209 & 122 & 71 & 0.028 & 0.680 & 0.218 \\
\hline Root \% Carbon & 35.2 & 35.7 & 35.4 & 35.3 & 1.13 & 0.632 & 0.749 & 0.400 \\
\hline Leaf $\%$ Nitrogen & 5.42 & 4.83 & 5.58 & 5.71 & 0.36 & 0.070 & $<0.001$ & 0.010 \\
\hline Root \% Nitrogen & 4.43 & 3.88 & 4.98 & 4.86 & 0.27 & 0.003 & $<0.001$ & 0.032 \\
\hline Leaf \% Sulfur & 1.16 & 0.28 & 1.23 & 0.29 & 0.08 & $<0.001$ & 0.210 & 0.220 \\
\hline Root \% Sulphur & 1.03 & 0.16 & 1.26 & 0.18 & 0.06 & $<0.001$ & $<0.001$ & $<0.001$ \\
\hline \multicolumn{9}{|l|}{$\begin{array}{l}\text { ACSOs and Amino } \\
\text { Acids } \mu \mathrm{g} / \mathrm{g} \text { fwt }\end{array}$} \\
\hline Leaf Arginine & 371 & 376 & 313 & 302 & 94.9 & 0.930 & 0.053 & 0.798 \\
\hline Leaf Asparagine & 459 & 552 & 672 & 1022 & 265 & 0.024 & 0.002 & 0.161 \\
\hline Leaf Glutamine & 730 & 1462 & 703 & 2163 & 1085 & 0.009 & 0.357 & 0.322 \\
\hline Leaf MCSO & 114 & 5.3 & 68.9 & 5.1 & 12.5 & $<0.001$ & $<0.001$ & $<0.001$ \\
\hline Leaf 1-PECSO & 1034 & 100 & 1064 & 52.0 & 174 & $<0.001$ & 0.877 & 0.498 \\
\hline Root Arginine & 60.4 & 46.3 & 37.2 & 37.8 & 48.8 & 0.678 & 0.336 & 0.652 \\
\hline Root Asparagine & 134 & 208 & 200 & 537 & 195 & 0.007 & 0.009 & 0.060 \\
\hline Root ECSO & 33.8 & 46.7 & 34.8 & 50.6 & 13.6 & 0.007 & 0.580 & 0.749 \\
\hline Root Glutamine & 394 & 580 & 383 & 972 & 284 & 0.001 & 0.061 & 0.050 \\
\hline HAST BM192995 & 61.5 & 120 & 70.8 & 159 & 26.8 & $<0.001$ & 0.017 & 0.116 \\
\hline ATPS AF212154 & 51.3 & 20.7 & 38.2 & 7.1 & 16.3 & $<0.001$ & 0.028 & 0.965 \\
\hline APSR AF212155 & 53.4 & 159 & 66.6 & 166 & 22.1 & $<0.001$ & 0.189 & 0.673 \\
\hline SiR AF403293 & 192 & 186 & 160 & 119 & 70.4 & 0.311 & 0.051 & 0.453 \\
\hline SAT AF212156 & 257 & 224 & 215 & 223 & 60.2 & 0.542 & 0.283 & 0.320 \\
\hline SS1FT AJ006067 & 24.7 & 11.3 & 24.0 & 6.2 & 17.7 & 0.020 & 0.618 & 0.710 \\
\hline alliinase AF126049 & 194 & 165 & 156 & 362 & 157 & 0.108 & 0.144 & 0.040 \\
\hline
\end{tabular}


from cDNAs identified in this study for Allium gene mapping.

Our observation that transcript levels of HAST and APSR, and, to a lesser extent ATP sulfurylase, increase in CLK roots following transient $\mathrm{S}$ deprivation confirms observations made in other plants (Bolchi et al., 1999; Takahashi et al., 1997). Although our observation of lower root ATP sulfurylase expression at low steady-state $\mathrm{S}$ levels contradicts the reports of transient stress studies, it is consistent with biochemical studies that have used similar, longer-term treatments. A study of the effects of longterm $\mathrm{S}$ deprivation on rapeseed showed significant reductions in ATP sulfurylase activity over time (Lencioni et al., 1997). Recent studies of S metabolism in developing wheat endosperm showed that ATP sulfurylase activity was enhanced several-fold by high S nutrition and that it was likely to be rate-limiting in this system (Fitzgerald et al., 2001). Because ATP sulfurylase is the initiating reaction in the assimilation pathway it is an attractive candidate for pathway control (Hell, 1997). Pilon-Smits et al. (1999) demonstrated that transgenic Indian Mustard over-expressing ATP sulfurylase accumulated glutathione and sulfate and was more tolerant to the toxic sulfate analog selenate. Our observations of significant differences between cultivars and higher expression at high $\mathrm{S}$ suggests that this enzyme may be an important candidate for further comparative biochemical genetic comparisons of onion cultivars with divergent $\mathrm{S}$ metabolism phenotypes. However, it has been suggested that HAST (Takahashi et al. 1997) and APSR (Leustek et al., 2000) may also be key regulators of pathway, activity, and we observed higher HAST expression in Houston roots. Sulfate limitation has been shown to increase SiR enzyme activity in Allium tuberosum leaf (Takahashi et al., 1996a), but not to affect SiR transcript levels in Arabidopsis (Bork et al., 1998). Similarly, we observed no effect of S treatment on SiR transcript levels, though there was evidence for higher SiR expression in CLK roots. SAT activity is primarily regulated via allosteric interactions in the cysteine synthetase complex (Leustek and Saito, 1999) and different responses to S deprivation have been reported among Arabidopsis SAT transcripts (Takahashi et al., 1997).

We restricted our analyses of gene expression and metabolism in this study to prebulbing onion plants to facilitate the management and sampling of more plants per experimental unit, and to ensure we were sampling vigorous and healthy roots for biochemical analysis and RNA isolation. As bulbing is associated with major shifts in metabolism and partitioning of $\mathrm{S}$ compounds further studies are required to assess the relevance of our observations to mature bulb phenotypes. The most notable observation in this study is the significant differences in $\mathrm{N}$ partitioning between the two onion cultivars we compared. Randle (2000) demonstrated that $\mathrm{N}$ nutrition affects onion pungency and numerous studies in other systems have demonstrated interaction between $\mathrm{S}$ and $\mathrm{N}$ assimilation (Leustek et al., 2000). Other studies have reported similar accumulation of glutamine, asparagine and arginine under S deprivation (Amancio et al., 1997; Rigano et al., 2000) and suggested this causes down-regulation of nitrate reduction, maintaining N/S balance during S deprivation (Migge et al., 2000). Studies in Arabidopsis have demonstrated that response to $\mathrm{S}$ deprivation is regulated by $\mathrm{N}$ (Yamaguchi et al., 1999) and that the product of SAT, O-acetyl-serine, can cause up-regulation of HAST (Smith et al., 1997) and APSR (Koprivova et al., 2000). The significant cultivar $\times \mathrm{S}$ interactions we observed in $\mathrm{N}$ uptake and partitioning suggest that genotypic differences in pungency may be associated with differences in interaction between $\mathrm{N}$ and $\mathrm{S}$ primary metabolism. The SAT/cysteine synthetase complex is a key step connecting amino acid and $\mathrm{S}$ metabolism and, therefore, a likely candidate for mediating such effects. Urano et al. (2000) showed that feedback inhibition characteristics of SAT could account for high concentrations of the cysteine in Allium tuberosum compared to other higher plants.

Evidence is also emerging to suggest several molecular mechanisms that could explain the association between onion dry matter content and pungency. The genetic correlation between dry matter and pungency is well known by breeders and has been dissected by quantitative genetic (Lin et al., 1995) and gene mapping (Galmarini et al., 2001) approaches. Randle (1992) has also shown that $\mathrm{S}$ nutrition treatments affect bulb carbohydrate composition. Sucrose is now recognized as a key signal molecule in plant metabolism, and has been shown to coordinately regulate APSR and nitrate reductase expression in Arabidopsis (Kopriva et al., 1999). Another possible mechanism for common posttransciptional regulation of key carbohydrate, $\mathrm{N}$ and $\mathrm{S}$ metabolizing enzymes is phosphorylation mediated by 14-3-3 proteins (Chung et al., 1999). We identified several 14-3-3 homologues in the differential cDNA library.

The metabolic and gene expression responses we observed in this study were consistent with observations made in other species and will provide tools and a focus for further analysis in Allium systems, particularly in bulbing onion. We conclude that genetic differences in pungency phenotypes of the lines we compared may be due to different regulation of the sulfur assimilation pathway. We also conclude that such pungency differences may also be associated with different interactions between sulfur and nitrogen metabolism.

\section{Literature Cited}

Altschul, S.F., W. Gish, W. Miller, E.W. Myers, and D.J. Lipman. 1990. Basic local alignment search tool. Journal of Molecular Biology, 215:403-410.

Amancio, S., D.T. Clarkson, E. Diogo, M. Lewis, and H. Santos. 1997. Assimilation of nitrate and ammonium by sulphur deficient Zea mays cells. Plant Physiology \& Biochemistry, 35(1):41-48.

Bernhard, R.A. 1970. Chemotaxonomy: Distribution studies of sulphur compounds in Allium. Phytochemistry 9:2019-2023.

Bolchi, A., S. Petrucco, P.L Tenca, C. Foroni, and S. Ottonello. 1999. Coordinate modulation of maize sulfate permease and ATP sulfurylase mRNAs in response to variations in sulfur nutritional status: Stereospecific down-regulation by L-cysteine. Plant Molecular Biology, 39(3):527-537.

Bork, C., J.D. Schwenn, and R. Hell. 1998. Isolation and characterization of a gene for assimilatory sulfite reductase from Arabidopsis thaliana. Gene 212(1):147-153.

Chung, H., P. Sehnke, and R. Ferl. 1999. The 14-3-3 proteins: Cellular regulators of plant metabolism. Trends In Plant Science, 4(9):367-371.

Fitzgerald, M.A., T.D. Ugalde, and J.W. Anderson. 2001. Sulphur nutrition affects delivery and metabolism of $S$ in developing endosperms of wheat. Journal of Experimental Botany, 52(360):1519-1526.

Foyer, C.H., F.L. Theodoulou, and S. Delrot. 2001. The functions of inter- and intracellular glutathione transport systems in plants. Trends Plant Sci. 6(10):486-492.

Freeman, G.G. and N. Mossadeghi. 1970. Effect of sulphate nutrition on flavour components of onion (Allium cepa). J. Sci. Food Agr. 21:610-615.

Freeman, G.G. and R.J. Whenham. 1975. A survey of volatile components of some Allium species in terms of S-alk(en)yl-L-cysteine sulphoxides present as flavor precursors. J. Sci. Food Agr. 26:1809-1886.

Galmarini, C.R., I.L. Goldman, and M.J. Havey. 2001. Genetic analyses of correlated solids, flavor, and health-enhancing traits in onion (Allium cepa L.). Mol. Genet. Genom. 265(3):543-551.

Hell, R. 1997. Molecular physiology of plant sulfur metabolism. Planta 202:138-148.

Kopriva, S., R. Muheim, A. Koprivova, N. Trachsel, C. Catalano, M. Suter, and 
C. Brunold. 1999. Light regulation of assimilatory sulphate reduction in Arabidopsis thaliana. Plant J. 20(1):37-44.

Koprivova, A., M. Suter, R. Op den Camp, C. Brunold, and S. Kopriva. 2000. Regulation of sulfate assimilation by nitrogen in Arabidopsis. Plant Physiol. 122(3):737-746.

Kopsell, D.A. and W.M. Randle. 1999. Selenium affects the S-alk(en)yl cysteine sulfoxides among short-day onion cultivars. J. Amer. Soc. Hort. Sci. 124(3):307-311.

Kubec, R., M. vobodova, and J. Velisek. 2000. Distribution of S-alk(en)ylcysteine sulfoxides in some Allium species. Identification of a new flavor precursor: S-ethylcysteine sulfoxide (ethiin). J. Agr. Food Chem. 48(2):428-433.

Kushnir, S., E. Babiychuk, K. Kampfenkel, E. Bellesboix, M. Vanmontagu, and D. Inze. 1995. Characterization of Arabidopsis thaliana cDNAs that render yeasts tolerant toward the thiol-oxidizing drug diamide. Proc. Natl. Acad. Sci. USA 92(23):10580-10584.

Lancaster, J.E., J. Farrant, and M.L. Shaw. 2001. Sulfur nutrition affects cellular sulfur, dry weight distribution, and bulb quality in onion. J. Amer. Soc. Hort. Sci. 126(2):164-168.

Lancaster, J.E., J.F. Farrant, and M.L. Shaw. 2000a. Effect of sulfur supply on alliinase, the flavor generating enzyme in onions. J.Food Biochem. 24(5):353361.

Lancaster, J.E. and K.E. Kelly. 1983. Quantitative analysis of the S-alk(en)ylL-cysteine sulphoxides in onion (Allium cepa 1 .). J. Sci. Food Agr. 34:12291235.

Lancaster,J.E., M.L. Shaw, M.D.Pither-Joyce, J. McCallum, and M. McManus. 2000b. A novel allinase from onion (Allium cepa L.) roots: Biochemical characterization and cDNA cloning. Plant Physiol. 122:1269-1279.

Lancaster, J.E. and M.L. Shaw. 1989. Gamma-glutamyl peptides in the biosynthesis of S-alk(en)yl-L-cysteine sulphoxides (flavor precursors) in Allium. Phytochemistry 28:455-460.

Lancaster, J.E., and M.L. Shaw. 1994. Characterization of purified $\gamma$-glutamyl transpeptidase in onions: Evidence for in vivo role as a peptidase. Phytochemistry 36(6):1351-1358.

Lencioni, L., A. Ranieri, S. Fergola, and G.F. Soldatini. 1997. Photosynthesis and metabolic changes in leaves of rapeseed grown under long-term sulfate deprivation. J. Plant Nutr. 20(2-3):405-415.

Leustek, T., M.N. Martin, J.-A. Bick, and J.P. Davies. 2000. Pathways and regulation of sulfur metabolism revealed through molecular and genetic studies. Annu. Rev. Plant Physiol. Plant Mol. Biol. 51:141-165.

Leustek, T. and K. Saito. 1999. Sulfate transport and assimilation in plants. Plant Physiol. 120:637-643.

Lin, M., J.F. Watson, and J.R. Baggett. 1995. Inheritance of soluble solids and pyruvic acid content of bulb onions. J. Amer. Soc. Hort. Sci. 120(1):119-122.

Maw, G.A. 1982. Biochemistry of S-methyl-L-cysteine and its principal derivatives. Sulfur Rpt. 2(1):1-32.

McCallum, J.A., D.G. Grant, E.P. McCartney, J. Scheffer, M.L. Shaw, and R.C. Butler. 2001a. Genotypic and environmental variation in bulb composition of New Zealand adapted onion (Allium cepa) germplasm. N.Z. J. Crop \& Hort. Sci. 29(3):149-158.

McCallum, J.A., D. Leite, M. Pither-Joyce, and M.J. Havey. 2001b. Expressed sequence markers for genetic analysis of bulb onion (Allium cepa. L.). Theor. Appl. Genet. 103:979-991.

Migge, A., C. Bork, R. Hell, and T.W. Becker. 2000. Negative regulation of nitrate reductase gene expression by glutamine or asparagine accumulating in leaves of sulfur-deprived tobacco. Planta 211(4):587-595.

Nielson, K.K., A.W. Mahoney, L.S. Williams, and V.C. Rogers. 1991. X-ray fluorescence measurements of $\mathrm{Mg}, \mathrm{P}, \mathrm{S}, \mathrm{Cl}, \mathrm{K}, \mathrm{Ca}, \mathrm{Mn}, \mathrm{Fe}, \mathrm{Cu}$, and $\mathrm{Zn}$ in fruits, vegetables, and grain products. J. Food Comp. Anal. 4(1):39-51.

Ohsumi, C., T. Hayashi, and K. Sano. 1993. Formation of alliin in the culture tissues of Allium sativum. Oxidation of S-allyl-L-cysteine. Phytochemistry 33(1):107-111.

Pike, L.M., R.S. Horn, and C.R. Andersen. 1988. 'Texas Grano 1015Y': A mild pungency, sweet, shortday onion. Hortscience 23:634-635.

Pilon-Smits, E.A.H., S.B. Hwang, C.M. Lytle, Y.L.Zhu, J.C. Tai, R.C. Bravo, Y.C.Chen, T.Leustek, and N. Terry. 1999. Overexpression of ATP sulfurylase in Indian Mustard leads to increased selenate uptake, reduction, and tolerance. Plant Physiol. 119(1):123-132.
Platenius, H. and J.E. Knott. 1941. Factors affecting onion pungency. J. Agr. Res. 62:371-380.

Randle, W.M. 1992a. Onion germplasm interacts with sulfur fertility for plant sulfur utilization and bulb pungency. Euphytica 59(2-3):151-156.

Randle, W.M. 1992b. Sulfur nutrition affects nonstructural water-soluble carbohydrates in onion germplasm. HortScience 27(1):52-55.

Randle, W.M. 2000. Increasing nitrogen concentration in hydroponic solutions affects onion flavor and bulb quality. J. Amer. Soc. Hort. Sci. 125(2):254259.

Randle, W.M., M.L. Bussard, and D.F. Warnock. 1993. Ontogeny and sulfur fertility affect leaf sulfur in short-day onions. J. Amer. Soc. Hort. Sci. 118(6):762-765.

Randle, W.M., D.E. Kopsell, D.A. Kopsell, and R.L. Snyder. 1999. Total sulfur and sulfate accumulation in onion is affected by sulfur fertility. J. Plant Nutr. 22(1):45-51.

Randle, W.M. and J.E. Lancaster. 2001. Sulphur compounds in alliums in relation to flavour and quality. In: H. Rabinowitch and L. Currah (eds.). Allium crop science-Recent advances. CAB Intl., Wallingford, U.K.

Randle, W.M., J.E. Lancaster, M.L. Shaw, K.H. Sutton, R.L. Hay, and M.L. Bussard. 1995. Quantifying onion flavor compounds responding to sulfur fertility-Sulfur increases levels of alk(en)yl cysteine sulfoxides and biosynthetic intermediates. J. Amer. Soc. Hort. Sci. 120(6):1075-1081.

Rea, P.A., Z.S. Li, Y.P. Lu, Y.M. Drozdowicz, and E. Martinoia. 1998. From vacuolar GS-X pumps to multispecific ABC transporters. Annu. Rev. Plant Physiol. Plant Mol. Biol. 49:727-760.

Rigano, V.D., V. Vona, S. Carfagna, S. Esposito, P. Carillo, and C. Rigano. 2000. Effects of sulfate-starvation and re-supply on growth, $\mathrm{NH}^{4+}$ uptake and starch metabolism in Chlorella sorokiniana. Austral. J. Plant Physiol. 27(4):335-342.

Rose, T.M., E.R. Schultz, J.G. Henikoff, S. Pietrokovski, C.M. McCallum, and S. Henikoff. 1998. Consensus-degenerate hybrid oligonucleotide primers for amplification of distantly related sequences. Nucleic Acids Res. 26(7):16281635 .

Schwimmer, S. and W.J. Weston. 1961. Enzymatic development of pyruvic acid in onion as a measure of pungency. J. Agr. Food Chem. 9:301-304.

Simon, P.W. 1995. Genetic analysis of pungency and soluble solids in longstorage onions. Euphytica 82:1-8.

Smith, F.W., M.J. Hawkesford, P.M. Ealing, D.T. Clarkson, P.J. Vandenberg, A.R. Belcher, and G.S. Warrilow. 1997. Regulation of expression of a cDNA from barley roots encoding a high affinity sulphate transporter. Plant J. 12(4):875-884.

Takahashi, H., M. Yamazaki, N. Sasakura, A. Watanabe, T. Leustek, J.d.A. Engler, G. Engler, M. van Montagu, and K. Saito. 1997. Regulation of sulfur assimilation in higher plants: A sulfate transporter induced in sulfate-starved roots plays a central role in Arabidopsis thaliana. Proc. Natl. Acad. Sci. USA 94:11102-11107.

Takahashi, S., W.C. Yip, T. Matsugami, and G. Tamura. 1996a. Effect of sulfur and nitrogen nutrition on derepression of ferredoxin-sulfite reductase in leek seedlings. J. Plant Res. 109(1096):363-368.

Takahashi, S., Y. Yoshida, and G. Tamura. 1996b. Purification and characterization of ferredoxin-sulfite reductases from leek (Allium tuberosum) leaves. J. Plant Res. 109(1093):45-52.

Urano, Y., T. Manabe, M. Noji, and K. Saito. 2000. Molecular cloning and functional characterization of cDNAs encoding cysteine synthase and serine acetyltransferase that may be responsible for high cellular cysteine content in Allium tuberosum. Gene 257(2):269-277.

Vijn, I., A. Vandijken, M. Luscher, A. Bos, E. Smeets, P. Weisbeek, A. Wiemken, and S. Smeekens. 1998. Cloning of sucrose-Sucrose 1fructosyltransferase from onion and synthesis of structurally defined fructan molecules from sucrose. Plant Physiol. 117(4):1507-1513.

Wall, M.M., A. Mohammad, and J.N. Corgan. 1996. Heritability estimates and response to selection for the pungency and single center traits in onion. Euphytica 87(2):133-139.

Yamaguchi, Y., T. Nakamura, E. Harada, N. Koizumi, and H. Sano. 1999. Differential accumulation of transcripts encoding sulfur assimilation enzymes upon sulfur and or nitrogen deprivation in Arabidopsis thaliana. Biosci. Biotechnol. Biochem. 63(4):762-766. 